Ligia Bahia $^{1}$

\title{
PUNIÇÃO PREVENTIVA PARA COIBIR NEGAÇÃO DE COBERTURAS
}

Preventive punishment to deter denial of coverage

${ }^{1}$ Universidade Federal do Rio de Janeiro. Rio de Janeiro/RJ, Brasil. Correspondência: Ligia Bahia. E-mail: ligiabahia55@gmail.com.

Recebido em: 07/10/2014. Aprovado em: 16/10/2014. 


\section{RESUMO}

Processos de definição e redefinição de normas de acesso a ações de serviços de saúde não são lineares nem desprovidos de ambiguidades. Os conflitos de interesses e os lobbies estão presentes na vida social. As barreiras judiciais para conter influências de agentes e racionalidades contrários ao uso de procedimentos essenciais para a garantia da vida foram reunidas em súmulas orientadoras sobre litigâncias em torno de atendimentos de emergência. A reincidência da principal empresa brasileira de planos de saúde em negar coberturas obrigatórias foi objeto de punição preventiva. O reconhecimento do dano individual e a reversão da maior parcela da multa aplicada para um hospital público conferiram à decisão um inequívoco estatuto social.

\section{Palavras-Chave}

Cobertura; Planos de Saúde; Punição Preventiva; Seguros de Saúde.

\section{ABSTRACT}

Processes for defining and redefining the laws for access to health and for healthcare services are generally neither linear nor free of ambiguity. Conflicts of interest or lobbying is observed within society. The legal barriers containing the influence of agents and reasoning contrary to the use of procedures essential to guaranteeing life have been summarized in reports on litigation surrounding emergency services. The second conviction levied against the largest Brazilian private healthcare provider because of its denial of obligatory coverage was the object preventive punishment. The recognition of individual damages and the reversal of most of the penalty incurred on a public hospital was a decision that was seen as an unequivocal social statute.

\section{Keywords}

Coverage; Healthcare Plans; Health Insurance; Preventive Punishment. 


\section{EMENTA}

PLANO DE SAÚDE. Pedido de cobertura para internação. Sentença que julgou procedente pedido feito pelo segurado, determinado que, por se tratar de situação de emergência, fosse dada a devida cobertura, ainda que dentro do prazo de carência, mantida. DANO MORAL. Caracterização em razão da peculiaridade de se cuidar de paciente acometido por infarto, com a recusa de atendimento e, consequentemente, procura de outro hospital em situação nitidamente aflitiva. DANO SOCIAL. Caracterização. Necessidade de se coibir prática de reiteradas recusas ao cumprimento de contratos de seguro saúde, a propósito de hipóteses reiteradamente analisadas e decididas. Indenização com caráter expressamente punitivo, no valor de um milhão de reais, que não se confunde com a destinada ao segurado, revertida ao Hospital das Clínicas de São Paulo. LITIGÂANCIA DE MÁ-FÉ. Configuração pelo caráter protelatório do recurso. Aplicação de multa. Recurso da seguradora desprovido e do segurado provido em parte. (TRIBUNAL DE JUSTIÇA DO ESTADO DE SÃO PAULO, QUARTA CÂMARA DE DIREITO PRIVADO, APELAÇÃO N. 0027158-41.2010.8.26.0564 - SÃO BERNARDO DO CAMPO, VOTO N. 18512, RELATOR: TEIXEIRA LEITE, JULGAMENTO: 18/07/2013)

\section{Introdução}

O voto unânime da $4^{\text {a }}$ Câmara do Direito Privado do Tribunal de Justiça de São Paulo (TJ-SP) contra a apelação da empresa Amil sobre os danos causados pela negação de atendimento de emergência é inédito quanto à intenção preventiva e pode estimular posicionamentos do Poder Judiciário que inibam práticas lesivas à saúde. A litigância inicial referiu-se à polêmica em torno da garantia contratual, especialmente ao cumprimento de prazos de carência, para atendimento de um paciente infartado que declarou ser portador de hipertensão (em oposição à inequívoca situação de emergência de um caso de falência cardíaca).

Problemas que envolvem empresas de planos de saúde ocupam parcela considerável das demandas em todas as instâncias do Poder Judiciário ${ }^{1,2}$. Os temas dos processos referem-se a negações ou postergações de coberturas, preços das mensalidades (por mudança de faixa etária ou não), manutenção dos vínculos após mudanças no perfil laboral e, ainda, ao pagamento de impostos e contribuições

\footnotetext{
${ }^{1}$ Levantamento realizado pelo Grupo de Pesquisa e Documentação do Empresariamento da Saúde da Universidade Federal do Rio de Janeiro constata que, entre os processos localizados sobre saúde (recurso especial, mandado de segurança e recurso mandado de segurança) entre os anos 2010 a 2013 , as coberturas de planos de saúde motivaram pelo menos metade das demandas relacionadas com assistência à saúde.

2 SCHEFFER, Mário. Coberturas assistenciais negadas pelos planos e seguros de saúde em ações julgadas pelo Tribunal de Justiça do Estado de São Paulo. Revista de Direito Sanitário, São Paulo, v. 14, p. 122-132, 2013. http://dx.doi.org/10.11606/issn.2316-9044.v14i1p122-131.
} 
sociais, ressarcimento ao Sistema Único de Saúde (SUS), multas e taxas. Portanto, as tensões e os conflitos que deságuam nos tribunais expressam a assimetria entre a pressão das empresas para reter demandas e adiar ou não pagar obrigações devidas e as necessidades de saúde.

Os vencedores desse jogo, tal como cabo de guerra, costumam ser os mais fortes e resistentes. $\mathrm{Na}$ saúde, as situações enfrentadas costumam ser dramáticas. Exemplos não faltam: pacientes em ambulâncias que não recebem autorização para internação; negação do uso de procedimentos e medicamentos reputados por profissionais de saúde como adequados; e demora ou impossibilidade para obter acesso a leitos especializados constituem peças de um repertório macabro. A sobreposição do sofrimento com a doença com o da insegurança de capacidade de pagamento impõe uma sobrecarga de estresse para pacientes e seus parentes.

Em termos internacionais, os hiatos de cobertura devido a critérios de elegibilidade (idade para ingressar em um plano e problemas pré-existentes) e os limites de acesso e utilização de ações e serviços de saúde vêm sendo reduzidos por sucessivas legislações voltadas à normatização de contratos mais abrangentes.

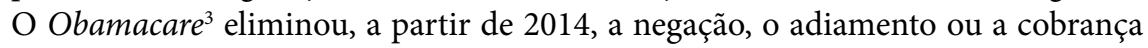
de coberturas por condições de saúde pré-existentes. A norma pretende superar as barreiras para impostas a um em cada dois norte-americanos adultos que possuem características que podem ser classificadas como pré-existência. Estar ou ter ficado doente não poderá mais ser um critério utilizado pelas empresas de planos de saúde nos Estados Unidos.

No Brasil, o arcabouço legal para regulamentar a atuação das empresas de planos de saúde - conformado pelas leis federais ns. $9.656 / 1998^{4}$, e 9.961/2000 - tem sido interpretado por inúmeras medidas administrativas restritivas de coberturas, inclusive algumas que alteraram a morfologia do mercado introduzindo alternativas para contornar preceitos legais, inclusive os que já limitavam as garantias mínimas previstas pelas leis aprovadas pelo Congresso Nacional. $\mathrm{Na}$ prática, as empresas de planos de saúde seguem comercializando produtos que: (a) não mantêm correspondência entre as coberturas previstas pela legislação

3 O Affordable Care Act (ACA), instituído em 2010 e oficialmente denominado The Patient Protection and Affordable Care Act (PPACA), é a legislação que reforma o sistema de saúde e a indústria de seguros e planos de saúde nos Estados Unidos. A lei busca aumentar a qualidade e disponibilidade de cuidados à saúde, incluindo segmentos populacionais não segurados por meio de dispositivos como impostos, subsídios, obrigatoriedade de coberturas e controle de preços. OBAMACARE FACTS. Disponível em: <http://obamacarefacts.com/pre-existing-conditions.php>.

${ }^{4}$ BRASIL. Lei n. 9.656 de 3 de junho de 1998. Dispõe sobre os planos e seguros privados de assistência à saúde. Disponível em: <http://www.planalto.gov.br/ccivil_03/leis/L9656compilado.htm>. Acesso em: 10 jun. 2015.

${ }^{5}$ BRASIL. Lei n. 9.961 de 28 de janeiro de 2000. Cria a Agência Nacional de Saúde Suplementar - ANS e dá outras providências. Disponível em: <http://www.planalto.gov.br/ccivil_03/leis/I9961.htm>. Acesso em: 10 jun. 2015. 
e os recursos assistenciais disponíveis; e (b) realizam ajustes de preços das mensalidades por meio de índices não oficiais. Nesse contexto, marcado pela atuação de determinadas empresas de forma pouco responsável com a saúde e com a vida dos clientes, o Poder Judiciário é a única via disponível para se obter direitos assistenciais.

\section{Falhas do mercado de planos e seguros}

Um contrato de plano privado de saúde não é o mesmo que atenção à saúde. Os planos são geralmente esquemas financeiros para o pagamento dos cuidados à saúde, não são serviços em si ou mesmo garantidores incondicionais de assistência. O hiato entre o plano de saúde e o cuidado à saúde pode decorrer de interpretações das normas legais e, ainda, da ausência de recursos assistenciais. $O$ caso que gerou o processo em questão enquadra-se no primeiro tipo: o de discordâncias sobre os limites de cobertura constantes nos contratos. No entanto, existem litigâncias geradas por dificuldade de se encontrarem vagas em hospitais ou mesmo especialistas que atendam determinados planos.

Hospitais, laboratórios e médicos tendem a priorizar as empresas e as situações com maiores valores de remuneração e que executam pagamentos em dia. Ambos os tipos de negação de cobertura são extremamente danosos para os pacientes e configuram práticas de proteção das empresas do pagamento de despesas. O primeiro deita raízes estreitas nas portas de entrada no sistema e o segundo, na organização de rede credenciada insuficiente e de má qualidade.

Falhas de mercado, especialmente aquelas que põem em rico a saúde, podem e devem ser controladas por políticas regulatórias contrapostas às tendências de seleção dos melhores riscos (isto é, procedimentos de menor custo) pelas empresas. A redução ou eliminação de carências e elegibilidade, especialmente para portadores de condições pré-existentes, e a obrigatoriedade de dispor de redes de serviços de saúde adequadas são instrumentos normativos essenciais para reduzir o racionamento assistencial. Outro elemento essencial à preservação do equilíbrio dos contratos é o preço das mensalidades.

A regulamentação da operação de planos e seguros de saúde deveria voltar-se precipuamente a reduzir tais imperfeições ou, em termos mais diretos, assegurar direitos de uso de serviços necessários de saúde e impedir a expulsão de clientes que não suportam aumentos desproporcionais nos pagamentos. No entanto, as pressões exercidas pelas empresas do setor constituem vetores de direção e sentido contrários à abrangência de cobertura. No que concerne especificamente às litigâncias judiciais, a alegação implícita de fraudes dos usuários (uso indevido de serviços) evidencia uma posição de força. Não é plausível supor a simulação de um infarto agudo do miocárdio ou outros problemas graves com base em cálculos racionais objetivando ludibriar as empresas de planos e seguros. 
Ressalte ainda que a perspectiva "menos ações de saúde", ceca e meca dos empresários que visam a reduzir e a controlar os gastos assistenciais, colide frontalmente com as tendências demográficas e epidemiológicas. Nos países desenvolvidos, as despesas com saúde vêm aumentando em função da necessidade de prover cuidados integrais e integrados para seus cidadãos por mais tempo. O envelhecimento e a predominância de problemas crônicos conformam vetores com sentido e direção contrários à contração de gastos e cuidados.

\section{O mercado de planos e seguros de saúde no Brasil}

No Brasil, atuam 912 empresas de planos de saúde, sendo que as 25 maiores operadoras dominam aproximadamente $50 \%$ do mercado. O segmento conta com 50,7 milhões de brasileiros conveniados, o que garantiu ao setor um faturamento de R $\$ 108$ bilhões em 2013. Mais de 80\% do mercado são planos coletivos, oferecidos por empresas para seus funcionários ou por meio da adesão de pessoas a entidades e associações.

O segmento dos planos de saúde no Brasil é beneficiado pela renúncia fiscal no cálculo de imposto de renda de pessoa física e jurídica, além de outros subsídios e isenções fiscais e tributárias à oferta e à demanda. Uma novidade neste mercado é a entrada do capital estrangeiro no país. Principal doadora até agora nas eleições de 2014, a Amil (maior empresa de planos de saúde do Brasil, com cerca de seis milhões de clientes) foi comprada pela United Health, um dos maiores grupos de saúde dos Estados Unidos. Em outro negócio recente, a Intermédica/Notre Dame foi adquirida pelo fundo Bain Capital.

É crescente a insatisfação dos brasileiros que usam planos de saúde, devido a uma série de fatores: exclusões de cobertura, barreiras de acesso para idosos e doentes crônicos, reajustes proibitivos de contratos, demora no atendimento, número de médicos, hospitais e laboratórios incompatível com a demanda e as necessidades de saúde dos usuários, baixa qualidade assistencial, problemas na relação entre planos e prestadores de serviços etc. A deterioração no atendimento tende a se agravar em função da expansão da comercialização de planos de saúde de baixo preço e rede insuficiente.

Recentemente, a oferta de planos individuais foi extinta e substituída pela comercialização de planos "falsos coletivos", que consiste na oferta de planos para dois ou mais indivíduos por meio de CNPJ ou adesão dissimulada em associações e entidades - o que permite aos contratos escaparem da regulação legal, tanto no que se refere ao reajuste de preços, quanto à proibição de rescisão unilateral e aos limites de cobertura.

Trata-se de um mercado em expansão, que procura ampliar suas atividades para segmentos situados na base da pirâmide de renda por meio de planos 
limitados - que atendem às expectativas de segurança de pessoas saudáveis, mas que funcionarão como inibidores de demandas tão logo os problemas requeiram atenção de alto custo e continuada. A dinâmica acelerada de incorporação de clientes por parte das empresas de planos de saúde no Brasil não tem sido ajustada aos requerimentos dos cuidados assistenciais essenciais ao prolongamento da vida

\section{Intermediação de interesses das empresas de planos e seguros de saúde}

Os lobbies não são regulamentados no país. No entanto, existem evidências da inclinação favorável à agenda privatizante de parlamentares ou governantes que receberam doações para suas campanhas eleitorais de empresas de planos de saúde ${ }^{6}$. Obviamente, tal propensão não tem como causa o recebimento de recursos para fins de divulgação de suas campanhas, na medida em que parte considerável desses candidatos possui compromissos anteriores com a defesa de interesses dos planos de saúde.

A associação da influência das empresas de planos sobre órgãos do Poder Legislativo e do Poder Executivo pode ser facilmente verificada na nomeação de representantes dos planos de saúde para cargos estratégicos da Agência Nacional de Saúde Suplementar (ANS), caracterizando um inequívoco caso de porta giratória. Nos últimos anos, vários diretores da ANS, inclusive um ex-presidente, foram oriundos de empresas de planos de saúde ou indicados por elas. Em 2013, um dos indicados, que havia omitido do currículo sua atuação anterior como defensor de planos privados de saúde, não foi nomeado em decorrência da denúncia de entidades representativas de pesquisadores de saúde pública. Contudo, em 2014, um ex-dirigente de entidade patrocinadora da ação no Supremo Tribunal Federal (STF) contra o ressarcimento ao SUS pelos planos de saúde foi alçado ao cargo de diretor do órgão que regula o setor.

No que se refere às pressões sobre o Poder Executivo, constam as reuniões de um grupo restrito de empresários com a Presidência da República para apresentação de projetos - entre os quais abertura irrestrita de investimentos estrangeiros, ampliação de créditos e aprovação de novos subsídios e isenções fiscais e tributárias -, bem como para ampliação do uso do fundo público para lastrear a expansão de um mercado de planos de saúde ${ }^{7}$. Aprovada pelo Congresso Nacional e sancionada pela presidente da República, a Medida Provisória

\footnotetext{
${ }^{6}$ SCHEFFER, Mário; BAHIA, Lígia. Representação política e interesses particulares na saúde: o caso do financiamento de campanhas eleitorais pelas empresas de planos de saúde privados no Brasil. Interface, Botucatu, v. 15, p. 947-956, 2011. http://dx.doi.org/10.1590/S1414-32832011000300030.

7 NERY, Natuza et al. União quer ampliar acesso a planos de saúde. Folha de S. Paulo, São Paulo, 27 fev. 2013. Disponivel em: <http://www1.folha.uol.com.br/fsp/cotidiano/95986-uniao-quer-ampliar-acesso-aplanos-de-saude.shtml>.
} 
n. $619 / 2013^{8}$, que tratou, entre outros temas, da cobrança de PIS/Cofins, permitiu mudança na base sobre a qual esses tributos incidem.

Os planos de saúde obtiveram a anistia das dívidas e a redução de $80 \%$ na base de cálculo, da qual foram excluídos os "custos assistenciais" das operadoras. Ou seja, ao alterar a base de incidência de contribuições sociais, a MP n. 619/2013 livrou as empresas de planos de saúde do pagamento de um elevado passivo tributário e as isentou, na prática, do pagamento de uma das fontes imprescindíveis para o financiamento do SUS. Por outro lado, esta medida provisória - que mudou a forma de aplicação de multas e anistiou previamente os planos de saúde reincidentes em infrações - foi vetada pela Presidência da República, após denúncias veiculadas pela grande imprensa.

Outros pontos da agenda das empresas de planos e seguros, tais como a extensão para os hospitais da abertura para a entrada de empresas e capital estrangeiros e as linhas de crédito, têm sido objeto de projetos no Congresso Nacional e tema frequente nos encontros dos empresários com os órgãos do Poder Executivo. Sinteticamente, a pauta das empresas de planos e seguros de saúde se restringe a dois pontos: (i) subsídios, deduções fiscais, isenções de taxas e multas e novas fontes de financiamento; e (ii) redução das coberturas contratuais. Preocupações com os hiatos sanitários do país e prioridades assistenciais estão ausentes de um ementário exíguo e voltado à obtenção de retornos financeiros de curto prazo, e não à melhoria das condições de saúde.

\section{Indenização de caráter punitivo}

A indenização de caráter punitivo proposta pelo voto n. 18.512 evidencia uma profunda compreensão das falhas estruturais do mercado de planos e seguros de saúde no Brasil e, ainda, das singularidades relacionadas ao atendimento de emergências clínicas. O relatório baseia-se não apenas na reincidência do problema de negação de coberturas para emergências, mas também no confronto e no descumprimento da legislação e da jurisprudência expressa na Súmula 103 do TJ-SP,

\footnotetext{
${ }^{8}$ BRASIL. Medida Provisória n. 619 de 6 de junho de 2013. Autoriza a Companhia Nacional de Abastecimento a contratar o Banco do Brasil S.A. ou suas subsidiárias para atuar na gestão e na fiscalização de obras e serviços de engenharia relacionados à modernização, construção, ampliação ou reforma de armazéns destinados às atividades de guarda e conservação de produtos agropecuários; altera as Leis $n^{\circ} 8.212$, de 24 de julho de 1991 e $n^{\circ} 8.213$, de 24 de julho de 1991, para dispor sobre a condição de segurado especial, o Decreto-Lei $n^{\circ}$ 167, de 14 de fevereiro de 1967 e a Lei $n^{\circ} 10.406$, de 10 de janeiro de 2002, para dispor sobre prazos do penhor rural, e as Leis $n^{\circ} 12.096$, de 24 de novembro de 2009 e $n^{\circ} 12.512$, de 14 de outubro de 2011; atribui força de escritura pública aos contratos de financiamento do Fundo de Terras e da Reforma Agrária, de que trata a Lei Complementar $n^{\circ}$ 93, de 4 de fevereiro de 1998, celebrados por instituições financeiras por meio de instrumentos particulares; institui o Programa Nacional de Apoio à Captação de Água de Chuva e Outras Tecnologias Sociais de Acesso à Água - Programa Cisternas; e dá outras providências. Disponível em: <http://www.planalto.gov.br/ccivil_03/_ato2011-2014/2013/Mpv/ mpv619impressao.htm>. Acesso em: 10 jun. 2015.
} 
editada em 2013. O relator menciona, ainda, a existência de casos idênticos julgados contra a Amil, o que caracteriza inclusive a litigância de má-fé.

O descabimento da imposição de cláusulas de carência para casos de emergência foi duplamente consignado. A recusa de cobertura em situações de risco de vida contraria a razão de ser da vinculação a um plano de saúde, e os casos de emergência são relativamente raros, considerando-se o conjunto de clientes da empresa. Portanto, a supremacia das razões financeiro-contábeis em detrimento da responsabilidade pela preservação da vida dos clientes configura uma tentativa de lucro adicional.

Com base nessas premissas - o somatório de atos desafiadores da legislação -, com o intuito de encontrar meios para evitar a repetição da ilicitude e despertar a noção de cidadania na empresa, aplicou-se a reparação punitiva. Indubitavelmente o descumprimento de normas que visam à proteção da vida é um sintoma de grave desequilíbrio institucional e requer sanções de cunho social, voltadas a desestimular a reiteração de procedimentos danosos à saúde.

O valor da multa aplicada, a princípio elevado, torna-se insignificante quando cotejado com as receitas amealhadas pela empresa. E o sentido pedagógico da punição concretiza-se por meio da destinação dos recursos a um hospital público. Assim, a polêmica em torno do dano moral individual é contemplada, mas a decisão desloca-se também para o âmbito social. Assim, o posicionamento repressivo do voto preserva o interesse coletivo e prestigia a fórmula de reparação do dano moral social para atos que rebaixam os padrões de qualidade de vida.

Condutas negativas e reiteradas que extrapolam o nível individual, julgadas como causadoras de danos sociais, contribuem para a elucidação da natureza inextrincavelmente coletiva e social dos planos de saúde e para o aprimoramento da jurisprudência. Embora as empresas aleguem que o Poder Judiciário exorbita suas funções ao intervir nas relações entre entes particulares, é necessário estabelecer um ambiente normativo-institucional equilibrado, no qual as partes cumpram o que foi por elas definido. Atendimentos de emergência não podem ser confundidos com a busca ilimitada e incondicional de procedimentos eletivos. Os argumentos relativos ao impacto da imponderabilidade de decisões judiciais sobre coberturas de saúde sobre um fundo finito de recursos não procede. Os fundos privados existentes devem prever garantias para toda e qualquer condição clínica emergencial dos pacientes.

A multa aplicada à Amil não resulta de uma exacerbação do Poder Judiciário, e sim é uma consequência das deficiências de um setor que se nutre inclusive das desigualdades de acesso aos tribunais. A pretensão de suprimir a judicialização em favor da solução no âmbito administrativo não responde aos flagrantes atos de desrespeito aos próprios contratos. Caracterizar a negação de cobertura para emergências como dano moral supra individual representa um acerto de diagnóstico e tratamento e uma mudança de prognóstico quanto à efetividade das decisões judiciais. 


\section{Referências}

NERY, Natuza et al. União quer ampliar acesso a planos de saúde. Folha de S. Paulo, São Paulo, 27 fev. 2013. Disponível em: <http://www1.folha.uol.com.br/fsp/cotidiano/95986uniao-quer-ampliar-acesso-a-planos-de-saude.shtml>.

SCHEFFER, Mário. Coberturas assistenciais negadas pelos planos e seguros de saúde em ações julgadas pelo Tribunal de Justiça do Estado de São Paulo. Revista de Direito Sanitário, São Paulo, v. 14, p. 122-132, 2013. http://dx.doi.org/10.11606/issn.2316-9044.v14i1p122-131.

SCHEFFER, Mário; BAHIA, Lígia. Representação política e interesses particulares na saúde: o caso do financiamento de campanhas eleitorais pelas empresas de planos de saúde privados no Brasil. Interface, Botucatu, v. 15, p. 947-956, 2011. http://dx.doi.org/10.1590/S1414-32832011000300030.

Ligia Bahia - Doutora em Saúde Pública pela Fundação Oswaldo Cruz; mestre em Saúde Pública pela Fundação Oswaldo Cruz; graduada em Medicina pela Universidade Federal do Rio de Janeiro. Professora Associada da Universidade Federal do Rio de Janeiro. Rio de Janeiro/RJ, Brasil.E-mail: ligiabahia55@gmail.com. 